\title{
“Once In, Good for Life"- Not Applicable Anymore
}

\author{
Karunathilake I.M.
}

\section{Introduction}

In the past, undergraduate medical education was considered sufficient to practice medicine throughout clinician's career. This notion of "once in, good for life" is not considered acceptable or correct anymore. The need for all the physicians to be up to date through a Continuing Medical Education (CME) and Continuous Professional Development (CPD) to ensure good medical practice is now well established. Therefore, physicians are committed to become lifelong learners. This is due to three reasons;

1. Medical knowledge is expanding exponentially

2. Practice of Medicine is ever changing and evolving

3. Changing expectations of patients

The constant stream of advances in healthcare means that medicine in the 21 st century is vastly complex. The increasing quantum of knowledge in medicine no longer allows physicians to retain all knowledge that is necessary to provide quality patient care (Densen, 2011). Over 34000 references are added to MEDLINE each month from 4000 journals, and the doubling time of medical knowledge is estimated to be approximately 5 years. Knowledge is expanding faster than the ability to assimilate and apply it effectively (Karunathilake, 2017).

Advances in technology, demographic and epidemiological transitions, a rapidly ageing population, double burden of noncommunicable diseases and emerging new infectious disease make practice of medicine ever changing and evolving (Beetham \& Sharpe, 2013).

\footnotetext{
Corresponding Author:

Professor and Head, Department of Medical Education, Head, WHO Collaborating Centre for Medical Education, Faculty of Medicine, University of Colombo, Sri Lanka.

Email: karunathilake@hotmail.com
}

Within a short time, management guidelines learnt during the medical schools can not only become obsolete, but wrong as well! One Good example is how the management of dengue has changed with availability of new knowledge and changing pattern of the disease.

At the same time, patients' needs and expectations are changing. Patients rightly want and need to know that they are getting the best care possible. This means that the role of the Medical Council in ensuring patients that the care and treatment they receive is of high quality and safe is tougher than ever before.

Continuing Medical Education (CME) and Continuous Professional Development (CPD)Do they mean the same?

The terms Continuing Medical Education (CME) and CPD have been used interchangeably in most of the countries. CPD is open to many interpretations and the term CME differs from CPD. However, there seems to be a lot of overlapping in the way CME and CPD are defined by the accreditation bodies (Jayarathne, 2016).

The regional guidelines on CME/CPD for South Asia, published by the WHO, define CPD as follows. "CPD is beyond clinical update, includes wide-range of competencies like research and scientific writing, multidisciplinary context of patient care, professionalism and ethical practice, communication, leadership, management and behavioural skills, team building, information technology, audit, and appropriate attitudinal change". In comparison, $\mathrm{CME}$ is defined as "updating clinical knowledge". Thus, CME is a component of CPD and CPD involves a wide range of skills required for medical practice.

The CPD credit system is one of the main methods of documenting CPD activities. However, there is no internationally standardized system for using CPD credits as the evidence of participation in CPD. Awarding 
CPD credits for different CPD activities seem to vary among countries. Furthermore, it is observed that the number of CPD credits required for relicense and consequences of noncompliance also varies among countries.

\section{Developing CPD policies for South East Asian Region}

The practices and policies for CPD are still evolving in many countries in SEAR.

Medical Council of India has made legislations on mandatory $\mathrm{CME}$, that all physicians are required to have 30 hours of CME every 5 years (Lewis, 2015). In Sri Lanka CPD is voluntary and Sri Lanka Medical Association has commenced National CPD Certificate programme for all the doctors. Since, CPD organizing bodies work independently and CPD schemes and CPD provision systems vary across the organizations, standards or criteria have not been set for quality assurance of CPD activities and CPD accreditation bodies are yet to be established in Sri Lanka (Jayarathne, 2016). The Association of Physicians of Bangladesh organize regular CME activities for their doctors in Bangladesh. However, CME is not a mandatory requirement to practice medicine in Bangladesh (APB, 2017).

Myanmar Medical Association (MMA) is the main organizing body which is responsible for organizing CPD activities for physicians in Myanmar but CPD is not a mandatory requirement for Myanmar doctors (MMA, 2017). The Indonesian Medical Association (IMA) and its district agencies are responsible for managing and monitoring $\mathrm{CME}$ programmes in Indonesia and CME is mandatory for re-licensing process. Every physician in practice is required to complete 250 credits every 5 years to achieve a certificate of competence and pass a competency test to have his/her license renewed. Similarly, in the Maldives doctors are required renew their license to practice through the licensing exam and all the doctors need to renew their license in every 5 years. However, doctors are not required to show evidence of participation in CPD activities as a requirement for licensing exam. Further, if there are licensing lapses, these doctors need to show that they have attended CPD activities as a requirement for licensing examination. Thus, CPD through a licensing exam is a mandatory requirement for Maldivian medical practitioners (MMDC, 2017). Further, it is also evident that mandatory CPD for physicians is yet to be established in both Thailand and Bhutan.

\section{Conclusion}

Doctors have to be lifelong learners in order to provide best care for the patients. The ever changing and evolving nature of the practice of Medicine, exponential expansion of medical knowledge and changing expectations of patients will make a move towards mandatory CPD and revalidation an essential component of the medical education process.

Currently CPD is a voluntary process in SEAR and yet to be established properly. Establishing a CPD system has become a priority in the process of improving medical education in the region.

\section{References}

Association of Physicians of Bangladesh, 2017 continuing Medical Education https:www.apbbd.org/what_cme.php

Beetham, H. \& Sharpe, R. [Eds.] (2013) Rethinking pedagogy for a digital age: Designing for 21 stcentury learning, Routledge.

Densen, P. (2011) Challenges and opportunities facing medical education, Transactions of the American Clinical and Climatological Association, 122, pp. 48-58.

Jayarathne, Y.G.S.W., Karunathilake, I.M. \& Marambe, K.N. (2016). Are South East Asian countries ready for revalidation process of physicians through mandatory continuing professional development (CPD) activities?. South-East Asian Journal of Medical Education, $10,1$.

Jayarathne, Y.G.S.W. (2016) Exploration of current status of Continuing Professional Development (CPD) among Sri Lankan grade medical officers to develop a CPD provision framework. MD Thesis, Postgraduate Institute of Medicine, University of Colombo, Sri Lanka.

Karunathilake, I.M. (2017). Technology Enhanced Learning with Limited Resources-Transforming Limitations into Advantages. South-East Asian Journal of Medical Education, 11, 1.

Lewis, A. et al (2015) CME credit systems in three developing countries: China, India and Indonesia. Journal of European CME, 4, pp.27411 http://dx.doi.org/10.3402/jecme.v4.27411.

Maldives Medical and Dental council 2017 Licensing Exam http://mmc.gov.mv/.

Myanmar Medical Association (2017) Continuing Medical education http://www.mmacentral.org/. 